\title{
ACCOMMODATIONS AND ACADEMIC PERFORMANCE: FIRST-YEAR UNIVERSITY STUDENTS WITH DISABILITIES
}

\author{
JEANETTE PARSONS \\ QUEEN'S UNIVERSITY \\ MARY ANN MCCOLL \\ QUEEN'S UNIVERSITY \\ ANDREA MARTIN \\ QUUEN'S UNIVERSITY \\ DAVID RYNARD \\ QUEEN'S UNIVERSITY
}

\begin{abstract}
Despite growing enrollment of university students with disabilities, they have not achieved academic parity with their non-disabled peers. This study matched 71 first-year university students with disabilities and students without disabilities on three variables: high school average when admitted to university, gender, and program of study. Both groups of students were compared on three measures of academic performance: GPA, failed courses, and dropped courses after first year of university. The relationship between accommodations and academic performance was also analyzed for students with disabilities. Even when matched on admission average, gender, and program of study, students with disabilities had a significantly lower GPA and were more likely to fail courses in their first year than their peers without disabilities. While note-taking in the classroom was associated with being less likely to drop a course, it was also associated with poorer academic performance, as was using a calculator or alternate format during exams. The more accommodations students lost in the transition from high school, the worse they performed academically at university. Students who lost human assistant support in the classroom and the use of a computer or a memory aid during exams had a significantly lower GPA and were more likely to fail courses in their first year of university compared with students who did not lose these accommodations. These findings have implications for accessibility offices and universities in supporting the access needs and academic success of students with disabilities.
\end{abstract}

Keywords: accommodation, academic performance, transition

\section{Résumé}

Malgré l'augmentation des inscriptions d'étudiants universitaires handicapés, ceux-ci n'ont toujours pas atteint la parité avec leurs pairs non handicapés. Cette étude a apparié 71 étudiants universitaires de première année non handicapés et avec handicap selon trois variables : la moyenne du secondaire lors de l'admission à l'université, le sexe et le programme d'études. Les deux groupes ont été comparés selon trois mesures de la performance à l'université : la moyenne générale, les échecs et l'abandon de cours après la première année d'université. La relation entre les mesures d'adaptation et la performance à l'université a également été analysée pour les étudiants handicapés. Même lorsqu'ils étaient appariés sur la base de la moyenne d'admission, du sexe et du programme d'études, les étudiants handicapés avaient une moyenne générale nettement inférieure et étaient plus susceptibles d'échouer dans leurs cours en première année que leurs pairs non handicapés. La prise de notes en classe est associée à une probabilité réduite d'abandonner un cours, mais elle est aussi associée à des résultats scolaires inférieurs, tout comme l'utilisation d'une calculatrice ou d'un format d'examen différent. Plus les étudiants perdent des mesures d'adaptation lors de la transition du secondaire, plus leurs performances à l'université sont mauvaises. Les étudiants qui ont perdu le soutien d'une tierce personne en classe et la possibilité d'utiliser un ordinateur ou un aidemémoire pendant les examens avaient une moyenne générale nettement inférieure et étaient plus susceptibles d'échouer à des cours pendant leur première année que les étudiants n'ayant pas perdu ces mesures. Ces conclusions ont des implications pour les bureaux d'accessibilité et les universités en ce qui concerne le soutien aux besoins d'accès et à la réussite universitaire des étudiants handicapés.

Mots-clés : mesures d'adaptation, performance à l'université, transition 


\section{Introduction}

Between 2010 and 2019, the percentage of students with disabilities in first-year studies at Canadian universities jumped from $9 \%$ to 22\% (Canadian University Survey Consortium, 2019). During the same period, the number of students seeking supports through Ontario university accessibility offices jumped from 21,643 to 42,000 students, a growth of nearly $50 \%$ (R. Dyck, personal communication, November 19,2019 ). This growth is partly explained by the increasing number of students being identified with disabilities in elementary and high school (People for Education, 2017). Better awareness and reduced stigma have also enabled more university students with mental health disabilities to seek supports.

Despite this growth, students with disabilities have not yet reached academic parity with other students (Dryer et al., 2016). Although graduation rates have increased for both groups, more students with disabilities than their non-disabled peers do not complete their university studies (Finnie et al., 2012). They are less likely to persist from years one to two because of low grades (Mamiseishvili \& Koch, 2011). Many also take longer to graduate or achieve lower grades than their peers without disabilities, which affects their options for further study or career entry (Coates \& Radloff, 2010). Understanding more fully the factors that influence academic success for students with disabilities is clearly needed (Mamiseishvili \& Koch, 2011).

The experiences of students with disabilities transitioning from high school to university have become a significant line of inquiry in efforts to understand these persistent outcomes, with a particular focus on academic accommodations. The process of obtaining academic accommodation has received considerable attention including how to educate students on the difference between high school and university processes, enhance their self-advocacy skills, and increase access (Kelepouris, 2014; Kohler, 1996; Kohler \& Field, 2003; Madaus et al., 2011; Shaw \& Dukes, 2013). Other researchers have analyzed the differences between the actual accommodations approved in high school compared to those students are given at university (Bolt et al., 2011; Cawthon \& Cole, 2010; Cawthon et al., 2015).

Despite the commonly held belief that accommodations support academic success, few researchers have examined their actual effect on academic performance for students with disabilities at university (Rath \& Roy- er, 2002). A thorough literature review yielded just four studies. These examined one of two influencing factors on academic performance: (a) the number of accommodations received, or (b) the act of students requesting accommodation.

Trammell (2003), assessing the impact of accommodations on academic achievement for 62 participants, found that with each additional accommodation received, the first-term grades for university students with ADHD increased when compared with their peers with learning disabilities (LD). The reverse was true for students with LD, as their grades dropped with each additional accommodation. In a study examining the effect of requesting accommodations on academic performance over four semesters, Dong and Lucas (2016) found that while 715 students identified as having a disability at their university, only $21 \%$ requested accommodations. In contrast to results found by Trammell (2003), students with $L D, A D H D$, or a mental health disability were significantly more likely to be in good academic standing if they requested accommodations. Of those who did not request accommodations, $15.4 \%$ withdrew from their studies during the study period. Requesting accommodations did not have a significant effect on academic standing for students with physical disabilities.

Other studies assessed the effectiveness of specific accommodations on academic performance. Using a longitudinal data set for 1,910 participants, Mamiseishvili and Koch (2011) examined the effect of self-reported accommodations on academic persistence. Persistence was defined as remaining enrolled throughout the first year and returning for the second year. Results showed that classroom accommodations such as readers, scribes, and note-takers were positively associated with academic persistence, but exam accommodations had no effect. Conversely, Kim and Lee (2016) found that two exam accommodations had the strongest effect on cumulative grade point average (GPA) for 1,055 participants: extra time and adaptive technology, while classroom accommodations were found to have no effect.

Even though findings were inconsistent, the above research offers some insight into the link between academic accommodation and academic success for students with disabilities at university. Requesting accommodations is positively associated with academic performance for students with LD, ADHD, and mental health disabilities, but has no association for students with physical disabilities. Receiving accommodation is 
particularly effective for students with ADHD but their effectiveness for students with LD is unclear. Classroom accommodations-especially note-takers, readers, and scribes-are positively associated with academic persistence, while some exam accommodations have a positive impact on cumulative GPA.

Despite these insights, the literature remains limited in several important ways. First, only the accommodations that students received at university were analyzed. These studies did not consider high school accommodations, and whether changes to them may have impacted student academic performance at university. Research has shown consistently that students receive accommodations at university that are substantially different from what they received in high school (Cawthon et al., 2015; Newman \& Madaus, 2015a, 2015b; Parsons et al., 2020). However, transition research to date has not yet included this information data in examining the relationship between accommodation and academic performance at university.

Second, these studies relied on self-reported accommodation information. Limitations of self-report data are well-recognized in the field of transition for students with disabilities for their reliability and consistency complications. For example, Bolt et al. (2011) found a clear majority of Grade 12 students could not recall all of the accommodations for which they were approved, even though they attended their accommodation planning meetings. Third, all studies have design limitations in that they used single academic performance measures, and they compared students with and without disabilities on academic performance without matching them on known confounding variables.

\section{Study Purpose}

The present study seeks to address the above knowledge gaps in how accommodations affect academic performance for students with disabilities at university. This study will:

- Match students with and without disabilities on key variables

- Use three measures to assess academic performance: First-year GPA, and first-year dropped and failed courses

- Use high school and university accommodation data collected directly from file sources

This study has the following objectives:

1. Assess the impact of disability on academic performance for a cohort of students in their first year of studies at university

2. Assess the relationship between accommodations and academic performance for first-year university students

3. Assess the relationship between changes to accommodations and academic performance for first-year university students

\section{Method}

This study used a retrospective cohort design to look back in time at a cohort of first-year university students. Participants were classified on having a disability and receiving academic accommodations. Other intervening variables included gender, high school admission average, and program of study. The study design is depicted in Figure 1.

\section{Figure 1}

Study Design

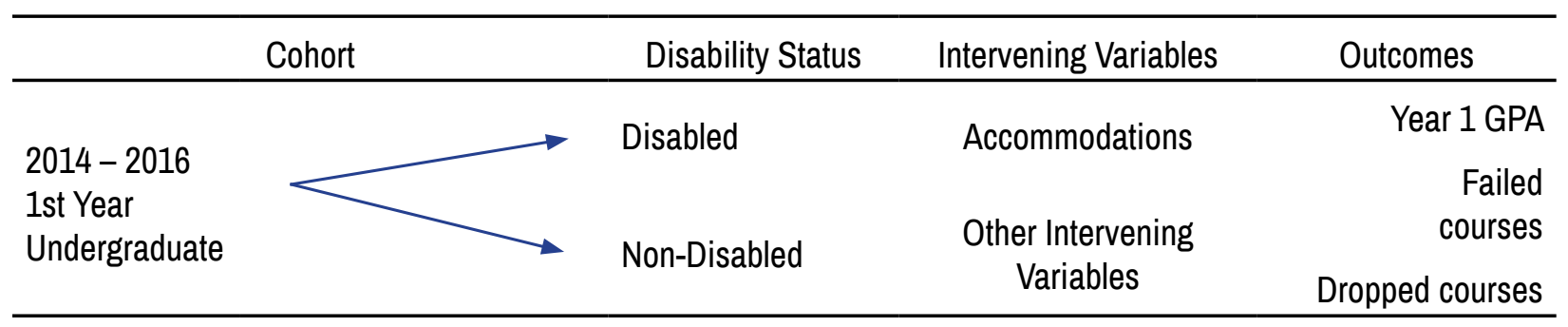




\section{Sample}

The study was conducted at a medium-sized university in southeastern Ontario.

\section{Inclusion Criteria}

Students were eligible to participate if they:

a) Entered university directly from high school in Fall 2014, 2015, or 2016

b) Had a formal or informal Individualized Education Plan (IEP) in their final year of high school

\section{Exclusion Criteria}

Potential participants were excluded if they:

a) Transferred from another post-secondary institution

b) Entered into any academic program other than first-year undergraduate studies

\section{Recruitment}

The full cohort consisted of 12,617 students. From this cohort, 1,495 students with disabilities were identified through the records of the university's Accessibility Services Office (ASO) between 2014 and 2016. The sample of disabled students was further reduced to 568 (38\%) by requiring them to have an Individualized Education Plan (IEP) from their final year in high school on the file.

These 568 students were invited to participate by email in early November 2016, with follow-up emails sent in December 2016 and January 2017. From this group of 568 students, 71 agreed to participate, for a total yield of $13 \%$.

The comparator sample of participants without disabilities was selected from the remaining 11,122 members of the cohort. Each student with a disability was matched with five (5) participants without disabilities. When using a small observational sample like in this study, pairing each participant in the observational group with up to five participants in the control group can provide a more precise benchmark for statistical comparison (Riniolo, 1999; White \& Sabarwal, 2014).

Participants were matched on the following variables: (a) year of admission, (b) faculty, (c) gender, and (d) high school admission average. Participants in the Education faculty were all enrolled in the concurrent program (e.g., students complete both a bachelor's degree in their field and a Bachelor of Education at the same time). Although the disability status of participants in the matched sample is unknown, none of them were registered with the ASO.

Table 1 summarizes the sample characteristics. Participants with or without disabilities did not differ significantly in their program of study or their year of registration or age, but the sample of participants with disabilities included significantly more females. The sample of participants with disabilities included participants with learning disabilities (LD, 49.3\%), psychiatric disabilities (which included ADHD), (38\%), and physical disabilities (12.7\%). Psychiatric disabilities include mental illness, autism spectrum disorder (ASD), and attention-deficit/ hyperactivity disorder (ADHD) because they must meet criteria set out in the Diagnostic and Statistical Manual of Mental Disorders. Physical disabilities include physical or functional disabilities (e.g., cerebral palsy), systemic or chronic diseases (e.g., Crohn's disease), vision or hearing loss, and acquired brain injury.

This study was granted ethics clearance and procedures employed were in accordance with requirements for research involving human participants as set by the university's Research Ethics Board. Written, informed consent was obtained from all study participants.

\section{Data Collection}

The following data was collected for this study.

\section{Exposure - Disability}

Disability was defined for this study as registration with the university ASO with documented evidence of a disability, and a high school IEP. Disability label identification was abstracted from the ASO file.

\section{Outcomes - Academic Performance}

The following university academic data was obtained from the university's Institutional Research and Planning office: (a) grade point average (GPA) after first year, and (b) number of failed and dropped courses in first year.

\section{Intervening Variables - Accommodation}

Academic accommodations data was collected directly from disabled students' IEPs (high school) and ASO (university) files using a specially designed abstraction tool called the Academic Accommodation Comparison Tool (AACT). The AACT identifies 27 accommodations most commonly offered to students in high school and undergraduate studies, classifying them as classroom 
Table 1

Sample Characteristics

\begin{tabular}{|c|c|c|c|c|c|}
\hline & & Disabled & & Non-disabled & \\
\hline Age & $M(S D)$ & $18.19(.434)$ & & $18.22(.406)$ & \\
\hline Admission Average & $M(S D)$ & $86.5(.585)$ & & $86.4(.256)$ & \\
\hline \multirow{3}{*}{ Sex } & & $N=71$ & $\%$ & $N=355$ & $\%$ \\
\hline & Female & 39 & 56.4 & 182 & 51 \\
\hline & Male & 32 & 43.5 & 173 & 49 \\
\hline \multirow{3}{*}{ Disability } & Psychiatric & 27 & 38.0 & & \\
\hline & Learning & 35 & 49.3 & $\mathrm{n} / \mathrm{a}$ & $\mathrm{n} / \mathrm{a}$ \\
\hline & Physical & 9 & 12.7 & & \\
\hline \multirow{3}{*}{ Enroll Year } & 2014 & 20 & 28.2 & 136 & 37.6 \\
\hline & 2015 & 34 & 47.9 & 152 & 43.8 \\
\hline & 2016 & 17 & 23.9 & 67 & 18.6 \\
\hline \multirow{5}{*}{ Faculty } & Arts \& Science & 52 & 73.2 & 252 & 71.4 \\
\hline & Engineering & 10 & 14.1 & 54 & 15.3 \\
\hline & Education & 4 & 5.6 & 19 & 5.2 \\
\hline & Commerce & 3 & 4.2 & 8 & 2.4 \\
\hline & Nursing & 2 & 2.8 & 22 & 5.5 \\
\hline
\end{tabular}

(Instruction) and exam (Assessment) accommodations (Parsons et al., 2020). The AACT was pilot-tested and assessed for consistency and reliability by three reviewers using inter-coder agreement assessment and coding drift assessment (Creswell, 2014).

\section{Other Intervening Variables}

For both groups, the following data were obtained from the University's Institutional Research and Planning Office to control for possible influence in the analysis: (a) gender, (b) program of study, and (c) high school academic average upon admission to university. Where necessary, high school averages were converted to a GPA (4-point scale) using the Undergraduate Grading System Conversion guide published by the Ontario Medical Schools Application Services (2019). Given that age varied very little between both groups, this variable was not used in the analyses.

\section{Data Analysis}

The following summarizes the statistical analyses used in this study.

\section{Objective 1: Impact of Disability on Academic Performance}

This objective was assessed using t-tests to detect a difference between disabled and non-disabled students' academic performance at the end of their first year of university. 


\section{Objective 2: Relationship Between Academic Accommodations and Academic Performance}

The association between accommodations granted at university and academic outcomes (GPA, failures, and dropped courses) was initially tested using bivariate analyses (t-tests and chi-squares, depending on the level of measurement-ordinal or interval). Multivariate regression was then used to control for possible confounding variables in the relationship between outcomes, disability, and accommodations received at university. Intervening variables included disability, gender, and program of study. Linear block regression was used to test the model with GPA as the outcome, and logistic regression was used for the two binary outcomes (failures and dropped courses).

\section{Objective 3: Relationship Between Changes to Academic Accommodations and Academic Performance}

Using these same three models listed above, a second set of regressions was performed to assess the relationship between accommodations lost in transition from high school to university.

\section{Results}

The following summarizes the results for each study objective.

\section{Objective \#1: Assess the Impact of Disability on Academic Performance}

This study tracked three indicators of academic performance: GPA, course failure $(\mathrm{Y} / \mathrm{N})$, and course drop $(\mathrm{Y} / \mathrm{N})$. Results of bivariate analyses showed that disability affected two of these: GPA and failure rate (Table 2).

Despite being matched on admission average, gender, and program of study, the average GPA after the first year of university was significantly lower for participants with disabilities than for those without disabilities (2.73 versus 3.18). Grade point average was also significantly lower for males and participants enrolled in Engineering and Commerce programs, when compared to all other participants. Participants in Education obtained a significantly higher GPA than participants in other pro- grams. Students with disabilities also failed courses significantly more often ( $28 \%$ versus $10 \%$ ), as did male students ( $11 \%$ versus $3 \%)$.

No difference was seen between participants with and without disabilities in terms of dropping a course. Dropping a course, however, was significantly more likely for participants in Arts and Sciences than in other programs (47\% versus $20 \%$ ), and significantly less likely for participants in Engineering ( $11 \%$ versus $44 \%$ ), where students have less choice in course selection.

In an attempt to control for known confounders identified in the bivariate analysis (admission average, gender, and program of study), regression models were tested to estimate the effect of disability on each of the academic outcomes of interest. Results are presented in Table 3.

In a model that explained $37 \%$ of variance in GPA, disability was the most significant predictor, followed by program of study and admission average $(F(4,421)=$ $\left.62.362, \mathrm{p}<.01 ; R^{2}=.372\right)$. Logistic regression showed that students with disabilities were 18 times more likely to have failed a course than their non-disabled peers. Other significant variables in this model were gender and admission average.

Despite not being significant in the bivariate analysis (Table 2), when other variables were controlled, disability had a significant effect on dropping courses. Participants with disabilities were 1.7 times more likely to have dropped a course than participants without disabilities. Other significant variables in this model included admission average and Arts \& Science program.

\section{Objective 2: Assess the Relationship Between Academic Accommodations and Academic Performance}

The remaining analyses of the study focused on participants with disabilities. The average number of university accommodations recommended for participants with disabilities in this sample was $4.32( \pm 2.88)$. The number of university accommodations was not significantly associated with GPA, nor with failed or dropped courses. Table 4 shows that the accommodations most commonly recommended for participants were: extra time on exams (84.5\%), separate space for writing exams (77.5\%), use of a computer during exams (40.9\%), and note-taking in the classroom (38.0\%). 
Table 2

Bivariate Analysis - Effects on Academic Performance

\begin{tabular}{|c|c|c|c|c|}
\hline Variable & $\mathbf{N}$ & GPA (SD) & Fail (\%) & Drop (\%) \\
\hline \multicolumn{5}{|l|}{ Disability } \\
\hline Disability & 71 & $2.73(.108)^{*}$ & $28 \% *$ & 49 \\
\hline No Disability & 355 & $3.18(.036)$ & $10 \%$ & 38 \\
\hline \multicolumn{5}{|l|}{ Sex } \\
\hline Male & 221 & $3.05(.064)^{* *}$ & $11 \% *$ & 36 \\
\hline Female & 205 & $3.15(.040)$ & $3 \%$ & 43 \\
\hline \multicolumn{5}{|l|}{ Program } \\
\hline Arts \& Science & 304 & $3.06(.764)$ & 8 & $47^{* *}$ \\
\hline Other & 121 & $3.21(.679)$ & 5 & 20 \\
\hline Engineering & 64 & $3.07(.039)$ ** & 4 & $11^{* *}$ \\
\hline Other & 362 & $3.36(.093)$ & 7 & 44 \\
\hline Commerce & 11 & $3.09(.037)^{* *}$ & 7 & 6 \\
\hline Other & 415 & 3.48 (.138) & 0 & 42 \\
\hline Education & 23 & $3.13(.037)^{* *}$ & 13 & 58 \\
\hline Other & 403 & $2.69(.107)$ & 6 & 39 \\
\hline Nursing & 24 & $3.20(.524)$ & 0 & 0 \\
\hline Other & 402 & $3.10(.751)$ & 7 & 41 \\
\hline
\end{tabular}

Notes: ${ }^{*} p<.05,{ }^{* *} p<.01$

Of the 20 accommodations that participants could receive at university, only one classroom accommodation-note-taking-and three exam accommodations were found to be significantly correlated with academic performance: (a) alternative-to-print format, (b) use of a calculator, and (c) use of a computer. Surprisingly, results showed that receiving three of these accommodations was associated with poorer academic performance.

Those who had a note-taker in the classroom had a significantly lower GPA $(2.47+.80)$ compared with those who did not $\left(2.97+.84 ; t_{71}=2.604, p<.01\right)$. Similarly, those who used a calculator on their exams did not do as well $(1.94+1.03)$ as those who did not $(2.94+.81$; $\left.t_{71}=2.628, p<.01\right)$.

The percentage of participants who failed a course was also significantly higher for those who used a calculator during exams compared with participants who did not have this accommodation ( $80 \%$ vs. $18 \%$ ), $X^{2}=10.175, p<.01$. It was also higher for those who took exams using alternative-to-print format (AF) compared with those who did not $\left(67 \%\right.$ vs. $21 \%, X^{2}=7.074$, $p<.01$ ).

Dropping a course was significantly associated with having permission to use a computer during exams (62\% vs. $\left.40 \%, X^{2}=3.200, p<.05\right)$. Conversely, not having a note-taker in class was significantly associated with dropping a course as $36 \%$ of participants who had this accommodation dropped a course in first year compared to $70 \%$ who did not $\left(X^{2}=7.742, p<.01\right)$. 
Table 3

Regression Analysis of Academic Outcomes

\begin{tabular}{|c|c|c|c|c|c|c|}
\hline & \multicolumn{2}{|c|}{ GPA } & \multicolumn{2}{|c|}{ Failed Course } & \multicolumn{2}{|c|}{ Dropped Course } \\
\hline & B & $95 \% \mathrm{Cl}$ & $\operatorname{Exp}(B)$ & $95 \% \mathrm{Cl}$ & $\operatorname{Exp}(B)$ & $95 \% \mathrm{Cl}$ \\
\hline Disability & $.45^{* *}$ & {$[-0.60,-0.29]$} & $18.27^{* *}$ & {$[8.80,37.97]$} & $1.74^{*}$ & {$[0.99,3.07]$} \\
\hline Sex & .04 & {$[-0.09,0.16]$} & $.25^{* *}$ & {$[0.12, .55]$} & 1.08 & {$[0.68,1.71]$} \\
\hline Admission Average & $.09^{* *}$ & {$[0.07,0.10]$} & $.65^{* *}$ & {$[0.56, .75]$} & $.94^{* *}$ & {$[0.89,0.99]$} \\
\hline \multicolumn{7}{|l|}{ Program } \\
\hline Arts \& Science & -3.16 & {$[-5.14,-1.18]$} & 1.07 & {$[0.20,5.89]$} & $15.56^{* *}$ & {$[2.04,118.85]$} \\
\hline Commerce & -.18 & {$[-0.48,0.13]$} & 8.418E.9 & {$[-,--]$} & 23.26 & {$[0.01,50500.10]$} \\
\hline Education & $-.41^{*}$ & {$[-0.66,-0.15]$} & 2.79 & {$[0.33,23.49]$} & 26.64 & {$[2.87,229.01]$} \\
\hline Engineering & -.16 & {$[-0.37,0.05]$} & .47 & {$[0.07,3.33]$} & 1.97 & {$[0.22,17.98]$} \\
\hline Nursing & -.15 & {$[-0.50,0.21]$} & 1.20 & {$[0.10,13.85]$} & 1.49 & {$[0.08,26.61]$} \\
\hline $\mathrm{R}^{2}$ model $=.372$ & & & & & & \\
\hline
\end{tabular}

Notes: ${ }^{*} p<.05 ;{ }^{* *} p<.01$

\section{Objective 3: Assess the Relationship Between Changes to Academic Accommodations and Academic Performance}

Table 4 also lists the accommodations that participants with disabilities lost or gained when they transitioned from high school to university. The accommodation changes shown in grey in the table appear to be lost but in reality, they are not noted as accommodations since greater autonomy at university means all students can access these supports.

The average number of accommodations lost in transition was $6.34( \pm 5.98)$. The most frequently lost accommodations were human assistance in the classroom (77.5\%) and during exams (25.4\%), and permission to use a computer during exams (31\%). Only one accommodation was offered significantly more often in university than in high school: taking an exam in a private space.

The more accommodations participants with disabilities had in high school, the lower their GPA at university $(r=-.263, p<.05)$. Having more accommodations in high school was also negatively associated with failed courses in first-year university $\left(t_{71}=-2.595, p<.05\right)$. The more accommodations participants lost as they transitioned from high school to university, the lower their GPA $(r=-.256, p<.05)$, and the more likely they were also to fail a course in their first year $\left(t_{71}=-2.289, p<.05\right)$.

Regression was used to estimate the effect of losing accommodations on academic outcomes in firstyear university for participants with disabilities. Results using 95\% confidence intervals are presented in Table 5 . The model tested explains $33 \%$ of variance in GPA $\left(F(8,62)=3.866, p<.01, R^{2}=.333\right)$. Losing the human assistance accommodation in the classroom, memory aids, or a computer during exams had a significantly negative association with GPA. Admission average continued to be significantly positively associated with GPA at the end of first year.

Logistic regression showed that losing these same three accommodations was also significantly related to failing courses in the first year, as was admission average. Losing accommodations had no significant effect on whether students dropped courses in their first year. 


\section{Table 5}

Losing Accommodations \& Academic Performance

\begin{tabular}{lcccc}
\hline & \multicolumn{2}{c}{ GPA } & \multicolumn{2}{c}{ Failed Courses } \\
Demographic & B & Cl 95\% & Exp(B) & Cl 95\% \\
\hline Gender & .183 & {$[-0.18,0.55]$} & .466 & {$[0.13,1.64]$} \\
Admission Average & $.062^{* *}$ & {$[-0.02,0.11]$} & .979 & {$[0.92,1.05]$} \\
Classroom Accommodations & & & & \\
Human Assistance & $-.537^{*}$ & {$[-1.05,-0.02]$} & 7.855 & {$[0.90,68.73]$} \\
Exam Accommodations & & & & \\
Breaks & -.007 & {$[-0.001,-0.02]$} & .908 & {$[0.21,3.94]$} \\
Calculator & -.022 & {$[-0.04,-0.01]$} & 1.514 & {$[0.19,11.81]$} \\
Computer & $-.443^{*}$ & {$[-0.88,-0.01]$} & 2.271 & {$[0.46,11.13]$} \\
Extra Time & -.188 & {$[-1.63,1.25]$} & .000 & - \\
Memory Aids & $-.755^{* *}$ & {$[-1.23,-0.28]$} & 6.786 & {$[1.06,43.44]$} \\
$\mathrm{R}^{2}$ model $=.333$ & & & & \\
\hline Notes: ${ }^{*}<<.05^{* *}{ }^{*}<.01$ & & & &
\end{tabular}

\section{Discussion}

Enrollment of students with disabilities at university has risen sharply in recent years, as has their access to accommodation supports on campus. Despite these improvements, a tenacious lag in the academic outcomes for these students remains when compared with their non-disabled peers. This lag is evidenced by their significantly lower academic persistence and graduation rates, both of which are influenced by academic performance.

This matched cohort study examined the effect of disability and academic accommodations on academic performance for first-year university students with disabilities. The main findings are highlighted in this discussion.

\section{Impact of Disability on Academic Performance}

Having a disability was significantly associated with poorer academic performance, despite participants be- ing matched on gender and program of study and having the same high school average when they entered university. The GPA for students with disabilities after the first year of university was significantly lower, and they also failed more courses than participants without disabilities. This result contrasts with previous research, which compared unmatched participants with and without disabilities, finding that GPA did not differ between the two groups (Adams \& Proctor, 2010). However, it aligns with more resent research that matched participants on age, gender, ethnicity, and parental education, and found that participants with disabilities were a full letter grade behind their non-disabled peers (Weyandt et al., 2013).

This outcome strongly suggests that admission average may not have the same predictive value of academic success at university for students with disabilities as it does for other students. This may be particularly true when considering high school accommodations because they may overestimate a student's readiness for university studies. For example, students who receive double time and other significant accommodations may perform very well in high school, but struggle to replicate 
this performance when such supports are reduced or removed at university (Lovett, 2011; Lovett \& Lewandowski, 2014).

It is important to note that information about disability severity was not collected in this study. It is possible that this particular sample of participants may have had more severe disabilities that impacted their academic performance compared with a different sample. Social factors not captured, which may have also influenced performance, include students moving away from home for the first time, or encountering unfamiliar accessibility barriers in housing, social activities, and transportation. Performance may have also been affected by academic factors including variation in course loads, poorly developed metacognitive skills, or ineffective study skills.

\section{University Accommodations and Academic Performance}

Positive correlations were found between academic performance and only four academic accommodations. Surprisingly, three accommodations were associated with poorer academic performance for participants who received them compared to those who did not. Participants who had a note-taker in the classroom or were permitted to use a calculator during an exam had a significantly lower GPA in first year than participants without these accommodations. Participants permitted to use a calculator or alternative-to-print format (AF) for their exams were more likely to fail a course in their first year at university compared with participants who did not have these accommodations. Participants were less likely to drop a course if they had the note-taking accommodation, but more likely to drop a course if they were permitted to use a calculator during exams. These findings contrast those from previous research, which found that accommodations were associated with better academic performance, including note-taking support and extra time on exams (Kim \& Lee, 2016; Mamiseishvili \& Koch, 2011).

Certain accommodations may be linked with poorer academic performance because, despite their convenience, they do not fully mitigate the effect of a student's disability on their academics. For example, permission to use a calculator during exams is typically granted to students with math deficits that impair their ability to grasp math language and symbols, recall abstract terms, or apply multi-step procedures. A calculator can help these students avoid careless errors or save time when performing simple math functions, especially on tests that are not assessing mere calculations (Lovett \& Lewandowski, 2014). However, for students with deficits like those indicated above, a calculator may not be sufficient to mitigate their effect on academic performance.

Similarly, using a computer for word processing as an accommodation can help with writing mechanics, such as spelling and grammar. It can also enable users to write longer answers in shorter time, making editing and organization easier (Hetzroni \& Shrieber, 2004). However, it does not boost idea generation, clarity of writing, content mastery, or persuasion of argument. If faced with deficits like these, it is not surprising that participants were more likely to drop courses, even if accommodated by using a computer during exams.

Despite being intended to improve access, some accommodations may inadvertently interfere with academic performance. Alternative-to-print format (AF) generally means converting text to audio using adaptive technology and is frequently recommended for students with vision, reading, or attention disabilities (Weis et al., 2017). Despite advancement, adaptive technology remains difficult to use because it may not always function as expected (Harrison, 2012; Holmes \& Silvestri, 2012). A computer voice cannot match a human reading aloud with proper enunciation and emphasis. Since it does not enable text skimming, AF can make reading short bits of information, such as on multiple choice exams, cumbersome and time-consuming (Bolt \& Thurlow, 2004, as cited in Lovett \& Lewandowski, 2014). As such, not all students develop the familiarity needed to use this technology effectively, especially during exams, which can negatively affect their academic performance.

Note-taking is another accommodation that may have unintended consequences for a student's academic performance. At the research site, the note-taking accommodation was provided by volunteers recruited from among students in each course. Volunteers and students, not identified to each other, upload and download notes through a confidential portal.

Taking and reviewing one's own notes in the classroom is associated with positive learning outcomes (Armbruster, 2009; Peverly et al., 2003). The kinesthetic act of taking down information in real time with a computer or pen and paper supports a student's engage- 
ment, learning, and comprehension (Maydosz \& Raver, 2010). Note-taking as an accommodation may be negatively associated with academic performance for the participants in this study because it deprived them of the learning effects inherent with taking one's own notes. Knowing a set of notes was being prepared for them, this accommodation may have reduced their active listening in class and their motivation for reviewing and expanding their notes after class.

Since the note-taking accommodation relied on volunteers, participant academic performance may have also been negatively affected when volunteers could not be recruited, or when their notes were of poor quality. Conversely, students may have been less likely to drop courses in which they consistently received quality notes from note-takers.

\section{Changes to Academic Accommodations and Academic Performance}

The more accommodations participants lost as they transitioned from high school to university, the lower their GPA and the more likely they were also to fail a course in their first year. The loss of three specific accommodations was also linked with a lower GPA and being more likely to fail a course: human assistance in the classroom, and the use of a computer or memory aid during exams.

All of the participants who had the memory aid accommodation in high school lost this accommodation once they arrived at university and just under half (43\%) lost permission to use a computer during exams. Nearly all participants (97\%) lost the human assistance accommodation in the classroom. This is consistent with previous research where $80 \%$ of students received individualized academic supports in high school, but less than $7 \%$ received similar supports at university (Newman \& Madaus, 2015a).

Some accommodations, like paraphrasing and repeating exam questions included in human assistance, are lost simply because they are not offered at university. Others are lost because the accommodation process differs from high school to university. In high school, a student without a formally diagnosed disability may still be granted accommodations if educators are concerned about their academic performance. At university, students are granted accommodations only with docu- mented verification of their disability and when accommodations can be linked directly to their disability. Poor academic performance is not a sufficient basis for receiving accommodations at university.

Some human assistance accommodations granted in high school may hinder skill development or independence, leaving some students ill prepared for university. Classroom assistance, such as repetitive presentation, can help make learning new material more predictable, and help with editing or work organization saves time. Unintentionally, these supports may actually inhibit students from developing the self-reliant strategies needed for independent learning at university (Newman \& Madaus, 2015b). Losing these supports may impact a student's academic performance because acquiring replacement skills once courses are underway in a fastpaced environment can be challenging.

The same is true for memory aids. This accommodation is recommended only for students who can learn and store new information, but have observable difficulties retrieving it (Harrison, 2019). When students with intact memories are permitted access to cues in a memory aid, they outperform other students writing the same exam without such cues (Duchnick et al., 2002). It is notable that all participants lost this accommodation once they arrived at university, suggesting they did not meet the documentation or disability criteria necessary for its approval. These students may have come to rely on memory aids for recalling information they should have learned. A memory aid may have also diminished their motivation for developing memorizing and recall strategies, leaving them unprepared for many of their first-year university exams.

For some students with disabilities, such as those with dysgraphia, using a computer during exams equalizes access. For other students, however, a computer can boost their performance by allowing them to write longer, better organized responses with fewer grammar errors in much less time (Gregg et al., 2007). With large class sizes and academic integrity concerns, many university instructors still administer exams using pen and paper. Participants who were unaccustomed to handwriting exams under time constraints and who lost the computer accommodation were likely at a significant disadvantage. Compared to using a computer, handwriting is much slower, makes corrections difficult, and can be distracting if students focus on the act of handwriting 
itself, rather than on what to write. All of these would negatively impact academic performance.

\section{Practice Implications}

The results of this study enhance our knowledge about the relationship between accommodations and academic performance for students with disabilities as they transition from high school to university. The negative relationship between having a disability and academic performance is worsened when students lose accommodations they received in high school once they arrive at university. Furthermore, receiving accommodations at university does not guarantee good academic performance.

These findings have several implications for high schools and universities supporting students with disabilities. To avoid unnecessary changes to accommodations, high schools should avoid using accommodations in place of teaching independent and learning strategy skills. They should also avoid granting accommodations specifically to support a student's academic performance if they cannot be linked directly to their disability.

Universities should be aware that high school admission average may not be a good predictor of academic success for students with disabilities compared with their non-disabled peers. Consequently, accessibility offices should collect information about high school accommodations, noting how they change once students arrive at university. This information should then be used to inform learning strategy programs for all students with disabilities, which ought to be customized to address specific learning deficits that result when familiar accommodations are removed.

For all students, universities ought to expand their use of universal design for learning (UDL). Canadian universities demonstrated their capacity for this in response to the COVID-19 pandemic and did so in record time. For example, many instructors who traditionally administered exams requiring heavy memory recall successfully switched to online assessments using other types of evaluation. Using teaching techniques such as employing multiple modalities to present information, adding extra time to all exams when appropriate, and encouraging all students with a small grade credit to contribute toward a central set of class notes can replicate some of the supports available in high school. Doing so would enhance the transition experiences of students with disabilities and reduce the need for individualized accommodation, while improving accessibility for all students.

\section{Limitations and Future Research}

The generalizability of this study is limited by its small sample size of self-selected participants, data collected primarily from high schools and a single university in one province, and first-year academic data only. Other data not collected that may have influenced findings are disability severity and distinguishing between accommodations received and those that participants actually used.

Further research should expand the sample size using pan-Canadian data, ensuring a sufficient sample for comparison across disability types. It should also collect academic performance data for years two, three, and four, graduation data, disability severity, and distinguish between accommodations received and those participants actually used. Using this enhanced data, future research should explore the effect of specific accommodations on academic performance for university students using a different methodology. For example, comparing the academic performance of students with the same disability label and similar disability severity who use or do not use a computer or a calculator during exams.

\section{Conclusion}

This study matched students with disabilities with their non-disabled peers on four variables and compared them on three academic performance measures. The relationships between academic accommodations received at university, changes to accommodations between high school and university, and academic performance were analyzed for students with disabilities.

Having a disability significantly affects academic performance at university for many students, even after accounting for known confounding variables such as high school admission average. Certain university accommodations are associated with poorer academic performance for students with disabilities, such as note-taking support or using a calculator during exams. The more accommodations students lose as they transition from high school to university, the poorer their academic performance. Losing certain accommodations, like human assistance or permission to use a computer or memory aids during exams, is associated with a lower GPA. 
Since high admission average cannot reliably predict academic success for students with disabilities, universities should collect high school accommodation information to better customize learning strategy supports. Universally, Canadian universities should also advance their use of UDL principles, as capably demonstrated during the COVID-19 pandemic. Doing so would ease the transition for students with disabilities and reduce the need for individualized accommodation, while improving access for all students.

\section{Acknowledgements}

The authors gratefully acknowledge helpful feedback from the reviewers in preparing the final version of this paper.

\section{References}

Adams, K. S., \& Proctor, B. E. (2010). Adaptation to college for students with and without disabilities: Group differences and predictors. Journal of Postsecondary Education and Disability, 22(3), 166-184. https://eric.ed.gov/?id=EJ906691

Armbruster, B. B. (2009). Taking notes from lectures. In R. F. Flippo \& D. C. Caverly (Eds.), Handbook of college reading and study strategy research (pp. 220-248). Routledge.

Bolt, S. E., Decker, D., Lloyd, M., \& Morlock, L. (2011). Students' perceptions of accommodations in high school and college. Career Development for Exceptional Individuals, 34(3), 165-175. https://doi. org/10.1177/0885728811415098

Bolt, S. E., \& Thurlow, M. L. (2004). Five of the most frequently allowed testing accommodations in state policy. Remedial and Special Education, 24, 141-152. https://doi.org/https://doi.org/10.1177/0741 $\underline{9325040250030201}$

Canadian University Survey Consortium. (2019). Survey of first year students. Canadian University Survey Consortium. https://cusc-ccreu.ca/?page id=32\&lang=en

Cawthon, S. W., \& Cole, E. V. (2010). Postsecondary students who have a learning disability: Student perspectives on accommodations access and obstacles. Journal of Postsecondary Education \& Disability, 23(2), 112-128. https://eric.ed.gov/?q=EJ906696\&id=EJ906696

Cawthon, S. W., Leppo, R., Ge, J. J., \& Bond, M. (2015). Accommodations use patterns in high school and postsecondary settings for students who are $\mathrm{d} /$ Deaf or hard of hearing. American Annals of the Deaf, 160(1), 9-23. https://doi.org/10.1353/aad.2015.0012

Coates, H., \& Radloff, A. (2010). Involving people in learning. HERDSA News, 32(2), 20-21. https://www. herdsa.org.au/publications/all

Creswell, J. W. (2014). Research design: Qualitative, quantitative, and mixed methods approaches. Sage Publications.

Dong, S., \& Lucas, M. S. (2016). An analysis of disability, academic performance, and seeking support in one university setting. Career Development and Transition for Exceptional Individuals, 39(1), 47-56. https://doi.org/10.1177/2165143413475658

Dryer, R., Henning, M. A., Tyson, G. A., \& Shaw, R. (2016). Academic achievement performance of university students with disability: Exploring the influence of non-academic factors. International Journal of Disability, Development and Education, 63(4), 419-430. https://doi.org/10.1080/103491 2X.2015.1130217

Duchnick, J. J., Vanderploeg, R. D., \& Curtiss, G. (2002). Identifying retrieval problems using the California verbal learning test. Journal of Clinical and Experimental Neuropsychology, 24(6), 840-851. https:// doi.org/10.1076/jcen.24.6.840.8405

Finnie, R., Childs, S., \& Qiu, H. (2012). Patterns of persistence in postsecondary education: New evidence for Ontario. Higher Education Quality Council of Ontario. http://www.heqco.ca/en-ca/Research/ResPub/Pages/Patterns-of-Persistence-in-Postsecondary-Education-New-Evidence-for-Ontario.aspx

Gregg, N., Coleman, C., Davis, M., \& Chalk, J. C. (2007). Timed essay writing: Implications for highstakes tests. Journal of Learning Disabilities, 40(4), 306-318. https://doi.org/10.1177/00222194070400 $\underline{040201}$

Harrison, A. (2019). Summary guidelines for recom- 
mending memory aids as an academic accommodation in post-secondary education. Queen's University. https://www.queensu.ca/rarc/resources/ memory-aid-guidelines-summary

Harrison, A. G. (2012). Assessment and accommodation of students with learning disabilities at the postsecondary level in Canada: A special issue for psychologists in education. Canadian Journal of School Psychology, 27(1), 3-11. https://doi. org/10.1177/0829573512438470

Hetzroni, O. E., \& Shrieber, B. (2004). Word processing as an assistive technology tool for enhancing academic outcomes of students with writing disabilities in the general classroom. Journal of Learning Disabilities, 37(2), 143-154. https://doi.org/10.1177/ 00222194040370020501

Holmes, A., \& Silvestri, R. (2012). Assistive technology use by students with LD in postsecondary education: A case of application before investigation? $\mathrm{Ca}$ nadian Journal of School Psychology, 27(1), 81-97. https://doi.org/10.1177/0829573512437018

Kelepouris, C. (2014). Transition students with disabilities into higher education. Brigham Young University Education \& Law Journal, (1), 27-39. https:/l digitalcommons.law.byu.edu/elj/vol2014/iss1/3

Kim, W. H., \& Lee, J. (2016). The effect of accommodation on academic performance of college students with disabilities. Rehabilitation Counseling Bulletin, 60(1), 40-50. https://doi. org/10.1177/0034355215605259

Kohler, P. D. (1996). Taxonomy for transition programming: A model for planning, organization and evaluating transition education, services and programs. https://eric.ed.gov/?id=ed399722

Kohler, P. D., \& Field, S. (2003). Transition-focused education: Foundation for the future. The Journal of Special Education, 37(3), 174-183. https://doi.org/1 $0.1177 / 00224669030370030701$

Lovett, B. J. (2011). Extended time testing accommodations: What does the research say? National Assocation of School Psychologists, 39(8), 14-15. https://eric.ed.gov/?id=EJ934062

Lovett, B. J., \& Lewandowski, L. J. (2014). Testing accommodations for students with disabilities: Research-based practice. American Psychological Association.

Madaus, J. W., Banerjee, M., \& Merchant, D. (2011). Transition to postsecondary education. In J. M. Kauffman \& D. P. Hallahan (Eds.), Handbook of special education (pp. 571-583). Routledge.

Mamiseishvili, K., \& Koch, L. (2011). First-to-secondyear persistence of students with disabilities in postsecondary institutions in the United States. Rehabilitation Counseling Bulletin, 54(2), 93-105. https://doi.org/10.1177/0034355210382580

Maydosz, A., \& Raver, S. A. (2010). Note taking and university students with learning difficulties: What supports are needed? Journal of Diversity in Higher Education, 3(3), 177-186. https://doi.org/10.1037/ a0020297

Newman, L. A., \& Madaus, J. W. (2015a). An analysis of factors related to receipt of accommodations and services by postsecondary students with disabilities. Remedial and Special Education, 36(4), 208-219. https://doi.org/10.1177/0741932515572912

Newman, L. A., \& Madaus, J. W. (2015b). Reported accommodations and supports provided to secondary and postsecondary students with disabilities: $\mathrm{Na}$ tional perspective. Career Development and Transition for Exceptional Individuals, 38(3), 173s-181. https://doi.org/10.1177/2165143413518235

Ontario Medical Schools Application Services. (2019). OMSAS - GPA calculations. https://www.ouac.on.cal guide/omsas-gpa-calculations/

Parsons, J., McColl, M. A., Martin, A., \& Rynard, D. (2020). Students with disabilities transitioning from high school to university in Canada: Identifying changing accommodations. Exceptionality Education International, 30(3), 64-81. https://ir.lib.uwo.cal eeil

People for Education. (2017). Special education: 2017. https://peopleforeducation.ca/our-work/special-education-report-2017|

Peverly, S. T., Brobst, K. E., Graham, M., \& Shaw, R. (2003). College adults are not good at self-regulation: A study on the relationship of self-regulation, 
note taking, and test taking. Journal of Educational Psychology, 95(2), 335-346. https://doi. org/10.1037/0022-0663.95.2.335

Rath, K. A., \& Royer, J. M. (2002). The nature and effectiveness of learning disability services for college students. Educational Psychology Review, 14, 353-381. https://doi.org/10.1023/A:1020694510935

Riniolo, T. C. (1999). Using a large control group for statistical comparison: Evaluation of a between-groups median test. The Journal of Experimental Education, 68(1), 75-88. https://doi. org/10.1080/00220979909598495

Shaw, S., \& Dukes, L. (2013). Transition to postsecondary education: A call for evidence-based practice. Career Development and Transition for Exceptional Individuals, 36(1), 51-57. https://doi. org/10.1177/2165143413476881

Trammell, J. (2003). The impact of academic accommodations on final grades in a post-secondary setting. Journal of College Reading and Learning, 34, 76-89. https://doi.org/10.1080/10790195.2003. $\underline{10850157}$

Weis, R., Erickson, C. P., \& Till, C. H. (2017). When average is not good enough: Students with learning disabilities at selective, private colleges. Journal of Learning Disabilities, 50(6), 684-700. https://doi. org/10.1177/0022219416646706

Weyandt, L., DuPaul, G. J., Verdi, G., Rossi, J. S., Swentosky, A. J., Vilardo, B. S., O'Dell, S. M., \& Carson, K. S. (2013). The performance of college students with and without ADHD: Neuropsychological, academic, and psychosocial functioning. Journal of Psychopathology and Behavioral Assessment, 35(4), 421-435. https://doi.org/10.1007/ s10862-013-9351-8

White, H., \& Sabarwal, S. (2014). Quasi-experimental design and methods, methodological briefs: Impact evaluation 8. http://www.unicef-irc.org/KM/IE/

\section{Contact Information}

Jeanette Parsons

jeanette.parsons@queensu.ca 